\title{
A Practical Nonprobabilistic Reliability Assessment Method on Key Strata Shear Failure in Longwall Mining
}

\author{
Hebing Luan, ${ }^{1,2}$ Jiachen Wang, ${ }^{1}$ Guowei Ma, ${ }^{2}$ and Ke Zhang ${ }^{2,3}$ \\ ${ }^{1}$ Faculty of Resources and Safety Engineering, China University of Mining and Technology (Beijing), Beijing 100083, China \\ ${ }^{2}$ School of Civil, Environmental and Mining Engineering, The University of Western Australia, Perth, WA 6009, Australia \\ ${ }^{3}$ School of Resources and Safety Engineering, Central South University, Changsha, Hunan 410083, China \\ Correspondence should be addressed to Hebing Luan; ausluanking@hotmail.com
}

Received 15 March 2015; Accepted 25 May 2015

Academic Editor: Giuseppe Rega

Copyright (C) 2015 Hebing Luan et al. This is an open access article distributed under the Creative Commons Attribution License, which permits unrestricted use, distribution, and reproduction in any medium, provided the original work is properly cited.

\begin{abstract}
Roof cutting has long been a potential hazard factor in longwall panels in some diggings in China. Meanwhile, the key strata structural reliability, which provides an assessment on the stability of overlying roof strata, may be a significant reference for support design in underground coal mines. This paper aims to investigate a practical nonprobabilistic reliability assessment method on key strata. The mechanical tests and the hollow inclusion triaxial strain tests were conducted to measure relevant mechanical parameters and in situ stress. Furthermore, against the typical failure features in Datong Diggings, China, a shear failure mechanical model of key strata is proposed. Then, an allowable-safety-factor based nonprobabilistic stability probability assessment method is given. The sensitivity of geometrical dimensions and uncertainty levels of friction angle and cohesion are further studied. It is found that thickness and span of key strata have more dominative effect on key strata's stability compared with the other factor and the increase of uncertainty levels results in decrease of stability probability.
\end{abstract}

\section{Introduction}

Longwall (LW) mechanized mining methodology, contributing most of Chinese raw coal production, has been extensively applied all over the world. At the same time, roof collapse has long been one of the greatest hazards faced by underground coal miners. The hazardous nature of roof collapse can be illustrated from the national statistics of coal mine accidents. From the Chinese accident statistics, 274 accidents, involving 325 fatalities in 2013, occurred related to roof collapse. Among a diverse range of roof failure, roof cutting, resulting in massive roof strata instability and violent air blast, has been a serious threat in some diggings in China. In recent 30 years, more than 30 accidents triggered by roof cutting, which caused huge economic losses and heavy casualties, have been recorded in Datong Diggings, China. It can be evident from the statistics that roof cutting has a significant impact on the safety conditions. To minimize the risks, a clear understanding of roof strata structural stability and failure model is extremely necessary.
To date, extensive studies in these areas have been carried out. Roof collapse evolution process and stress distribution in overlying strata have been studied and characterized by many researchers $[1,2]$. In recent decade, the key strata (KS), contributing dramatically to the roof strata structure stability, have been the focus of investigative emphasis and hot spot. The most important outcome is the "key strata" theory $[3,4]$, which provides the theoretical basis for studying overlying strata structural stability. Further researches by Xu et al. [5, 6], Miao et al. [7], and Ju et al. [8, 9] refined the KS theory theoretically and practically. Towards the typical hazardous roof cutting in Datong Diggings, China, relevant researches also have been launched. Xiong [10] applied energy theory to approach the mechanism of roof cutting. Hou et al. [11] summarized roof cutting characteristics and analyzed possible influencing factors based on sufficient fieldwork experience in Datong Diggings. Liu et al. [12] set up a complex rock beam model to analyze the overlying strata shear slipping and applied it in engineering design. 
TABLE 1: HI triaxial strain testing result.

\begin{tabular}{lcccc}
\hline Principal stress type & Value $(\mathrm{MPa})$ & Azimuthal angle $\left(^{\circ}\right)$ & Dip angle $\left(^{\circ}\right)$ & Vertical stress $(\mathrm{MPa})$ \\
\hline$\sigma_{1}$ & 17.5 & 220 & -9 & 12 \\
$\sigma_{2}$ & 13.7 & -55 & 29 & 58 \\
$\sigma_{3}$ & 9.6 & 146 & 5 & \\
\hline
\end{tabular}

At the same time, as uncertainty extensively exists in engineering problems, which are commonly related to material properties, loads, and so forth, the probability model has been widely adopted in engineering design with the aim of quantifying the uncertainty with respect to the characteristics of uncertain variables [13-16]. Since entering 1990s, BenHaim [17, 18] and Elishakoff et al. [19] suggested using convex models to represent uncertainty. Based upon the convex model theory, nonprobabilistic reliability principle was first introduced by Ben-Haim [20] and then Ben-Haim and Elishakoff [21] proposed the possibility measure methodology. Based on interval arithmetic, a new nonprobabilistic reliability model for structural stability was presented by Guo et al. [22-24]. In their studies, the nonprobabilistic reliability index for structural systems was defined and some algorithms were proposed to calculate the nonprobabilistic reliability index. Compared to the traditional probabilistic model, the nonprobabilistic method requires less data known and needs no objective distribution function. This may alleviate the computational burden and may be a valid and reasonable alternative when available information on the uncertain parameters is limited.

This paper aims to give a theoretical solution for KS shear failure assessment in longwall mining panels and hereby propose a practical nonprobabilistic reliability assessment method. Through the present work, we expect to promote an allowable-safety-factor based nonprobabilistic reliability assessment method. Four main parts are included in the following text. Firstly, based on some coal mine in Datong Diggings, China, density and mechanical tests and hollow inclusion (HI) triaxial strain test in KS roof strata were carried out. Secondly, a KS shear failure model directing against the failure features in Datong Diggings is proposed. Thirdly, an allowable-safety-factor based reliability assessment method is proposed and applied in the coal mine. Effects of KS geometrical dimensions and parameter uncertainty levels are further studied. Finally, a conclusion is given.

\section{Engineering Background}

2.1. Site Description. The project case in this paper is located in Datong Diggings, Shanxi Province, China, which features hard roof strata and KS massive collapse. It currently produces approximately 10 million ton raw coal annually. The LW mechanized retreat mining method is applied in the working panel.

The $5^{\#}$ coal seam is being exploited in number 8301 working panel whose length is $2000 \mathrm{~m}$ and width is $200 \mathrm{~m}$. The roof strata of $5^{\#}$ coal seam are mainly composed of $13 \mathrm{~m}$ thick sandstone with a fraction of mudstone. Core samples are taken from different positions in the $5^{\#}$ coal seam roof strata to conduct density and shear box testing.

2.2. Density Test. Specimens were firstly prepared into standard cylinders with a diameter of $50 \mathrm{~mm}$ and length of $100 \mathrm{~mm}$. Then density was measured by electronic balance and vacuum pump unit. According to test result, the density interval is given by $\rho \in\left[2203.89 \mathrm{~kg} / \mathrm{m}^{3}, 2415.56 \mathrm{~kg} / \mathrm{m}^{3}\right]$.

2.3. Shear Box Test. The loading setup of shear box tests is shown in Figures 1(a) and 1(b). Four sets of beveled dies with different angles, $40^{\circ}, 50^{\circ}, 60^{\circ}$, and $70^{\circ}$, respectively, were employed in this study. Two groups of specimens were tested on a YAD-2000 testing machine. Some of the broken specimens are shown in Figure 1(c). The results are illustrated in Figure 2.

The friction angle and cohesion were estimated by applying least square method. As shown in Figure 2, the lines are well fit with the test results. Then, intervals of friction angle and cohesion are, respectively, given by $\varphi \in\left[37.304^{\circ}\right.$, $\left.38.938^{\circ}\right] ; c \in[3.371 \mathrm{MPa}, 3.722 \mathrm{MPa}]$.

2.4. Hollow Inclusion Triaxial Strain Test. As shown in Figure 3, a system composed of CSIRO hollow inclusion triaxial strain cells, a KJ327-F in situ stress monitoring station, and a calibration machine was applied to test the in situ stress in $5^{\#}$ coal seam roof strata. Three HI triaxial strain cells were distributed in the roof strata of KS. Through postprocessing of measured data, the in situ stresses are shown in Table 1.

The lateral stress coefficient is defined as the ration between the maximum principal stress and the vertical stress:

$$
K=\frac{\sigma_{\max }}{\sigma_{v}} .
$$

We substituted relevant parameters into (1) and obtained the calculated later stress coefficient as 1.45 .

\section{KS Shear Failure Model}

The key strata dominate the stability of the whole or most of the overlying strata and carry most of the overlying load. With the mining excavation advancing, the span of the KS keeps extending until internal stress reaches tensile strength or shear strength and the failure occurs [4]. Accordingly, the instability of KS may be triggered by shear failure or tensile failure. The geospatial location is shown in Figure 4.

It is observed that, in Datong Diggings, China, the massive roof collapses are usually caused by vertical cutting at both ends of short edge of LW panels. Shear failure is considered as the leading cause of roof cutting [11]. A simplified mechanical model is proposed, as shown in Figure 5. 


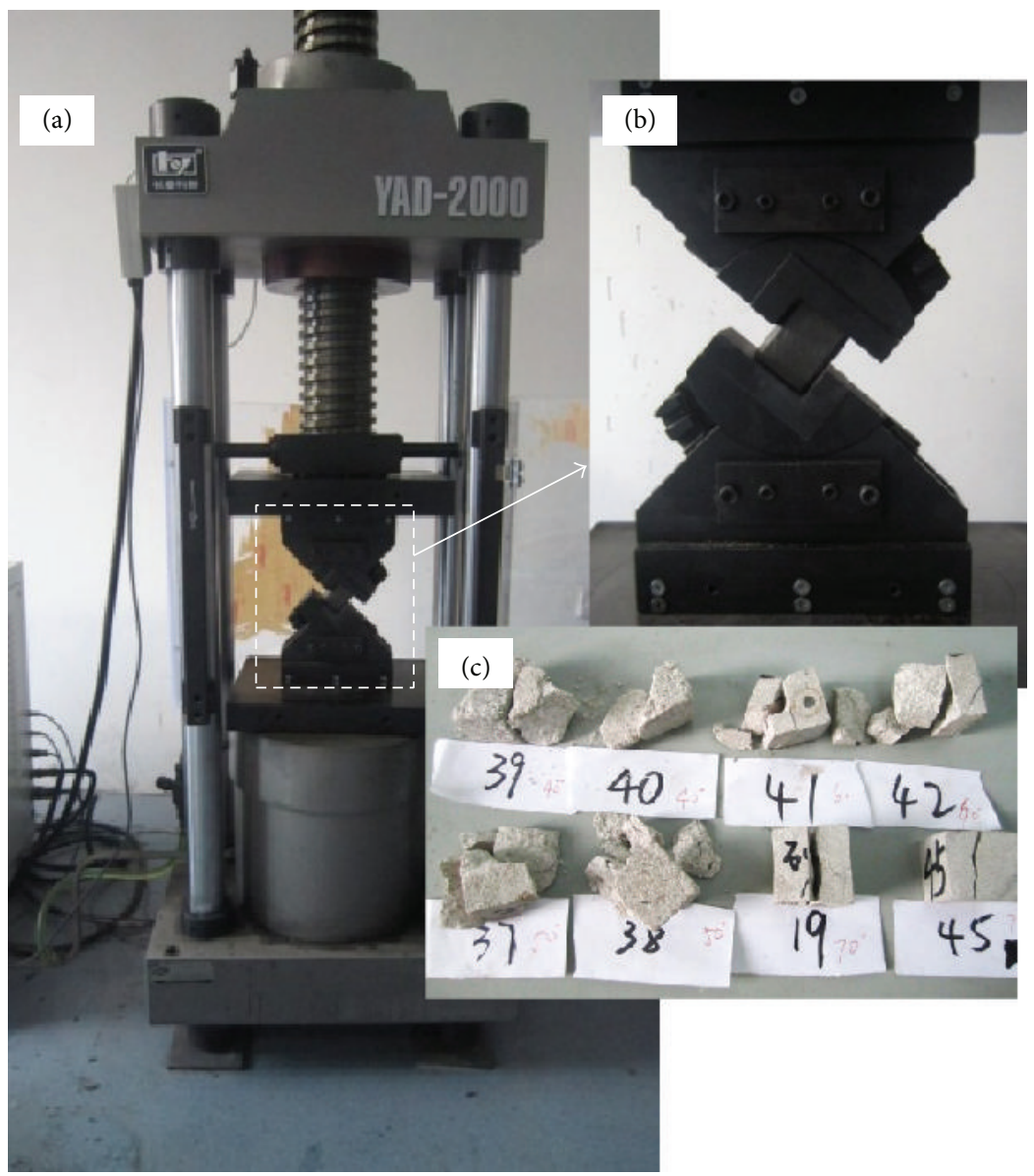

FIGURE 1: (a) YAD-2000 testing machine. (b) Adjustable die assembly. (c) Some failed specimens.
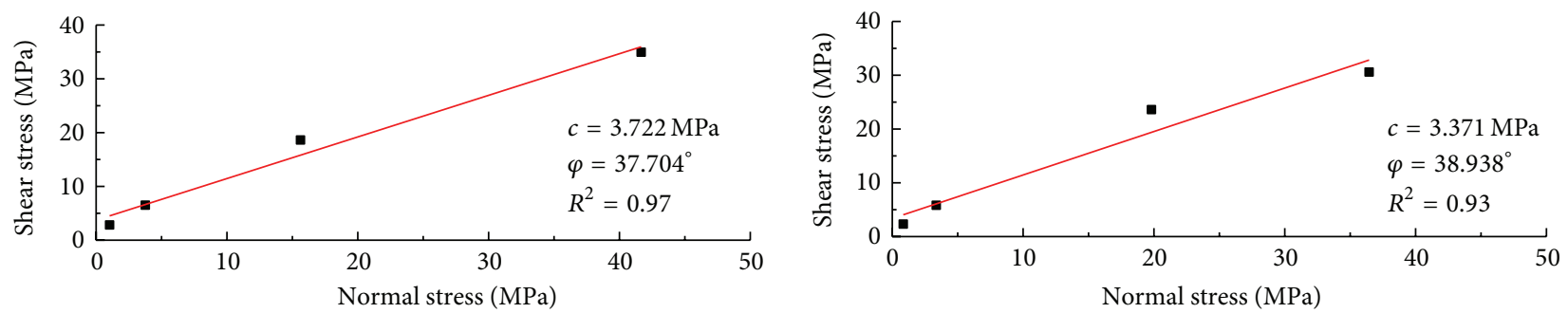

FIGURE 2: Shear box tests results.

As shown in Figure 5, we analyze a sheet element in the KS. Considering the limit state of KS, the sheet element attains equilibrium under the combined effect of self-gravity, pressure from upper surface, support from lower surface, and friction at both ends. The vertical stress equilibrium is given by

$$
\begin{aligned}
\sum F_{v}= & \int 2 a \rho g d z+2 a \sigma_{v}-\int 2 a\left(\sigma_{v}+d \sigma_{v}\right) d z \\
& -2 \int \tau_{f} d z=0,
\end{aligned}
$$

where $a$ is the half length of LW panel short edge, $\rho$ is the density, $\sigma_{v}$ is the vertical stress, and $\tau_{f}$ is the shear strength.
The relationship between the vertical stress and the horizontal stress is given by

$$
\sigma_{h}=K \sigma_{v}
$$

where $K$ is the lateral pressure coefficient and it differs from site to site due to diverse tectonic geology. The shear strength is given by the Coulomb criterion as

$$
\tau_{f}=\sigma_{h} \tan \varphi+c=K \sigma_{v} \tan \varphi+c,
$$

where $\varphi$ is the friction angle and $c$ is the cohesion. 


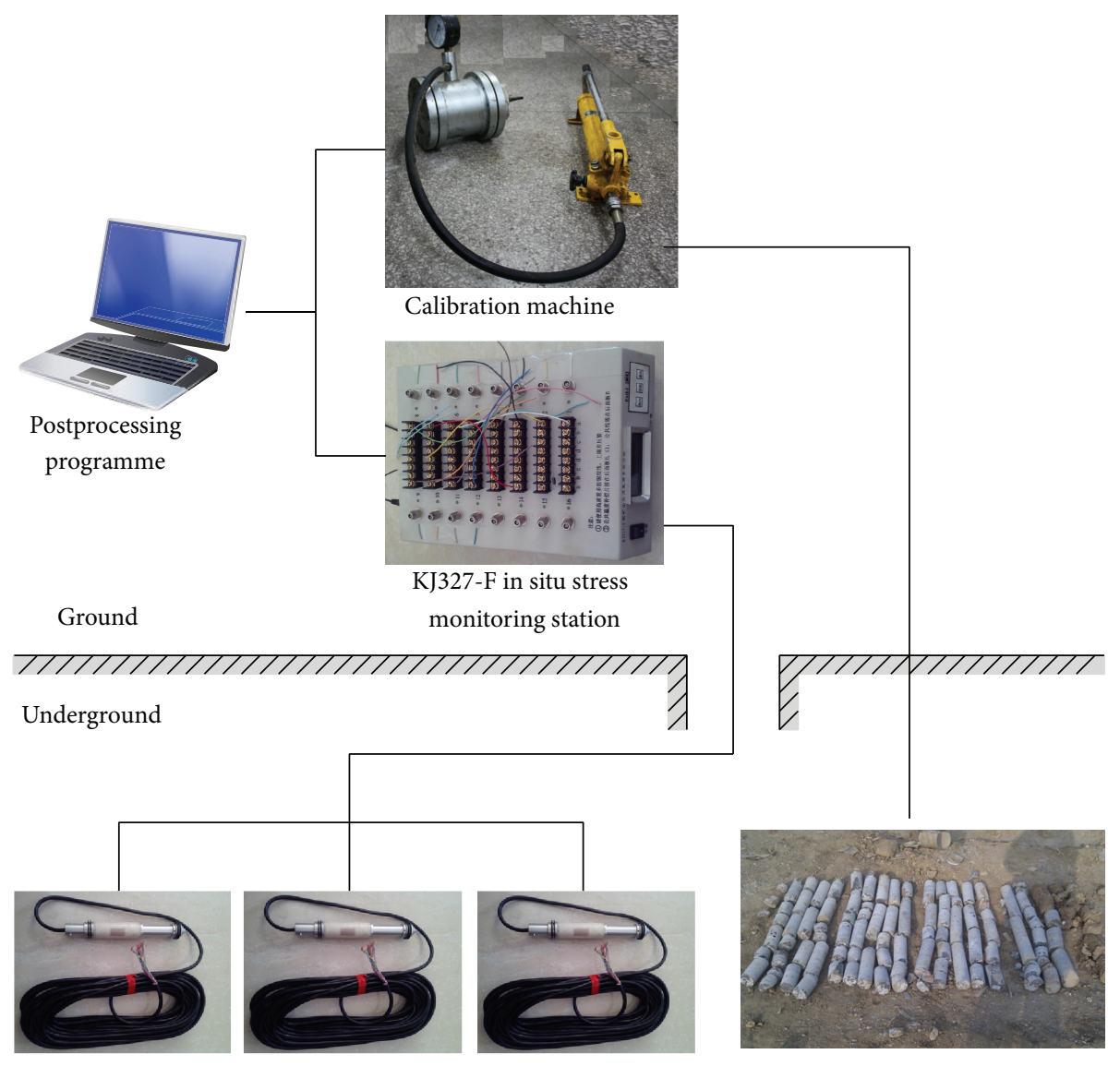

HI triaxial strain cells

Core samples

FIGURE 3: In situ stress testing system.

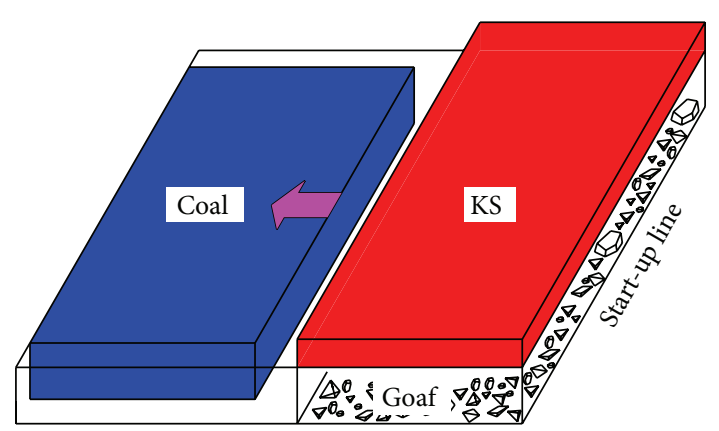

FIgURE 4: Geospatial location of KS.

Substituting (3) and (4) into (2), the vertical stress $\left(\sigma_{v}\right)$ is obtained by

$$
\sigma_{v}=\frac{a \rho g-c}{K \tan \varphi}\left(1+A e^{-(K \tan \varphi / a) z}\right) .
$$

Considering the boundary condition, when $z=0, \sigma_{v}=q$, where $q$ is the load from overlying strata. Thus, we get the particular solution of vertical stress:

$$
\sigma_{v}=\frac{a \rho g-c}{K \tan \varphi}+e^{-(K \tan \varphi / a) z}\left(q-\frac{a \rho g-c}{K \tan \varphi}\right) .
$$

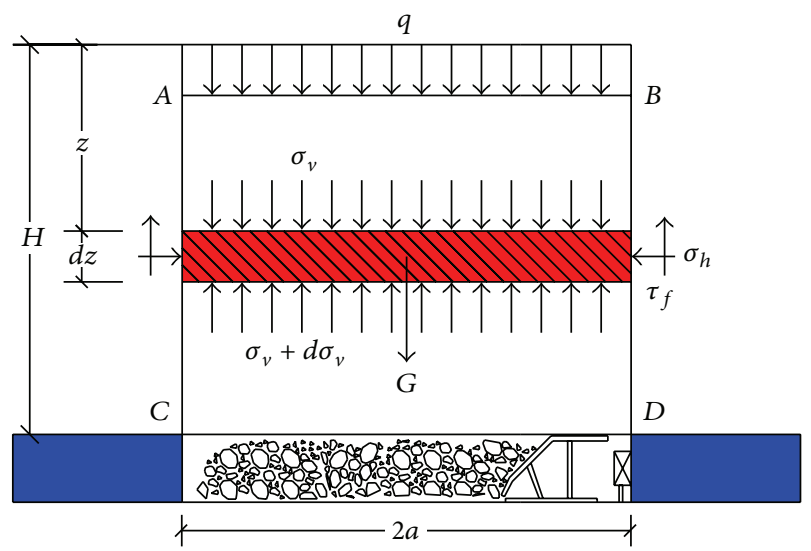

FIGURE 5: Mechanical model for roof shear failure.

Then the resisting force is given by

$$
\begin{aligned}
R & =L \int_{0}^{H}\left(K \sigma_{v} \tan \varphi+c\right) d z=L a(\rho g H \\
& \left.+\frac{(q K \tan \varphi-a \rho g+c)\left(1-e^{-K H \tan \varphi / a}\right)}{K \tan \varphi}\right),
\end{aligned}
$$




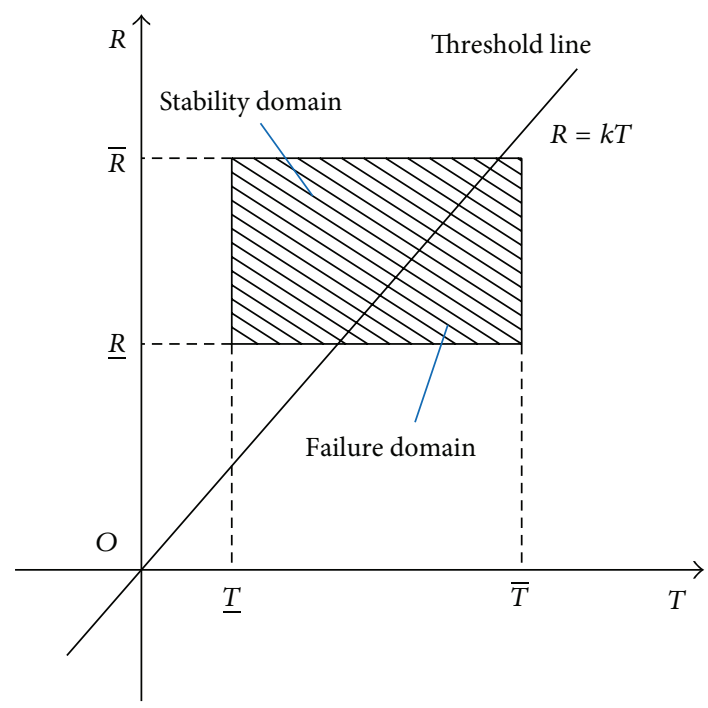

FIGURE 6: Schematic diagram of stability and failure domains.

where $L$ is the perimeter of KS and $H$ is the thickness of KS. The driving force is given by

$$
T=q \cdot S+\rho \cdot g \cdot V
$$

where $S$ and $V$ are the horizontal area and volume of KS, respectively.

\section{Reliability Assessment on KS Shear Failure}

4.1. Nonprobabilistic Reliability Model for KS Shear Failure. Based on the definition of interval number, $x=[x, \bar{x}]$, where $\underline{x}$ and $\bar{x}$ are the lower and upper bound [22]. The density and mechanical tests give three relevant interval numbers: $\rho=[\rho, \bar{\rho}]=\left[2203.89 \mathrm{~kg} / \mathrm{m}^{3}, 2415.56 \mathrm{~kg} / \mathrm{m}^{3}\right] ; \varphi=[\varphi, \bar{\varphi}]=$ $\left[37.70 \overline{4}^{\circ}, 38.938^{\circ}\right] ; c=[\underline{c}, \bar{c}]=[3.371 \mathrm{MPa}, 3.722 \mathrm{MPa}]$. By mechanical analysis on KS shear failure, the resisting force and the driving force are calculated. Here we also define the resisting force and driving force intervals as

$$
\begin{aligned}
R & =R\{[\underline{\rho}, \bar{\rho}],[\underline{\varphi}, \bar{\varphi}],[\underline{c}, \bar{c}]\}=[\underline{R}, \bar{R}] \\
T & =T[\underline{\rho}, \bar{\rho}]=[\underline{T}, \bar{T}] .
\end{aligned}
$$

Taking a new nonprobabilistic reliability analysis method by Wang et al. [25] and Liu et al. [26] for reference, which takes the ratio of the volume of safe domain to the total volume of the domain constructed by the basic interval variables as the measure of structural nonprobabilistic stability probability, the nonprobabilistic stability probability is defined as

$$
P_{s}=\frac{S_{\text {stability }}}{S_{\text {total }}}
$$

where $S_{\text {stability }}$ and $S_{\text {total }}$ are the stability domain area and total domain area, respectively, as shown in Figure 6.
4.2. An Allowable-Safety-Factor Based Method. The conception of allowable safety factors is widely employed in structure design and slope stability analysis. Here we define the allowable safety factor of KS as $1+\lambda$. It indicates that the slope of the threshold line in Figure 6 is equal to $1+\lambda$. According to different positional relation between the domain constructed by intervals and the threshold line, as shown in Figure 7, the allowable-safety-factor based nonprobabilistic stability probability is given as follows.

When $\underline{R} \geq(1+\lambda) \bar{T}$, as shown in Figure $7(\mathrm{a})$,

$$
P_{s}=1 \text {. }
$$

When $(1+\lambda) \bar{T}>\underline{R} \geq(1+\lambda) \underline{T}$ and $\bar{R} \geq(1+\lambda) \bar{T}$, as shown in Figure 7(b),

$$
P_{s}=1-\frac{[(1+\lambda) \bar{T}-\underline{R}](\bar{T}-\underline{R} /(1+\lambda))}{2(\bar{T}-\underline{T})(\bar{R}-\underline{R})} .
$$

When $(1+\lambda) \bar{T}>\underline{R} \geq(1+\lambda) \underline{T}$ and $\bar{R}<(1+\lambda) \bar{T}$, as shown in Figure $7(\mathrm{c})$,

$$
P_{s}=1-\frac{(\bar{T}+\underline{T}-2 \underline{R} /(1+\lambda))(\bar{R}-\underline{R})}{2(\bar{T}-\underline{T})(\bar{R}-\underline{R})} .
$$

When $\underline{R}<(1+\lambda) \underline{T}$ and $\bar{R} \geq(1+\lambda) \bar{T}$, as shown in Figure $7(\mathrm{~d})$,

$$
P_{s}=1-\frac{[(1+\lambda) \underline{T}+(1+\lambda) \bar{T}-2 \underline{R}](\bar{T}-\underline{T})}{2(\bar{T}-\underline{T})(\bar{R}-\underline{R})} .
$$

When $\underline{R}<(1+\lambda) \underline{T}$ and $(1+\lambda) \underline{T}<\bar{R}<(1+\lambda) \bar{T}$, as shown in Figure 7(e),

$$
P_{s}=\frac{[\underline{R}-(1+\lambda) \underline{T}](\bar{R} /(1+\lambda)-\underline{T})}{2(\bar{T}-\underline{T})(\bar{R}-\underline{R})} .
$$

When $\bar{R} \leq(1+\lambda) \underline{T}$, as shown in Figure $7(\mathrm{f})$,

$$
P_{s}=0 .
$$

4.3. Stability Probability Assessment for the Existing KS. Since there has not been a generally accepted stability probability standard for KS, we take correlative rock engineering standard [27] for reference. We take $\lambda=0.3$ in this study and substitute relevant parameters into (11a), (11b), (11c), (11d), (11e), and (11f). The calculated nonprobabilistic stability probability of the existing KS is $97.14 \%$ under the condition of no earthquake and no water. Overall, the KS are considered to be reliable for the threshold value according to the Grade I engineering requirement [27].

\section{Sensitivity Analysis}

5.1. Geometrical Dimensions Analysis. The effects of KS span and length were studied and are shown in Figures 8 and 9. To 


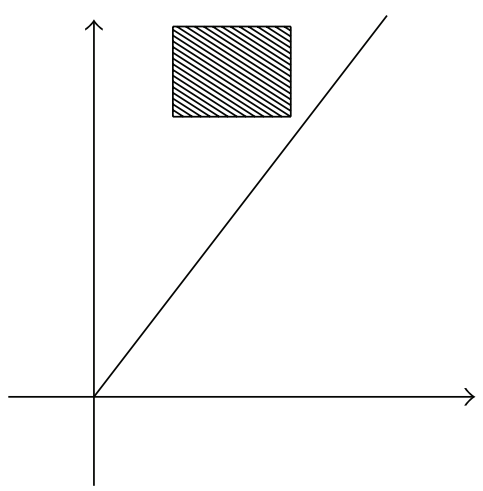

(a)

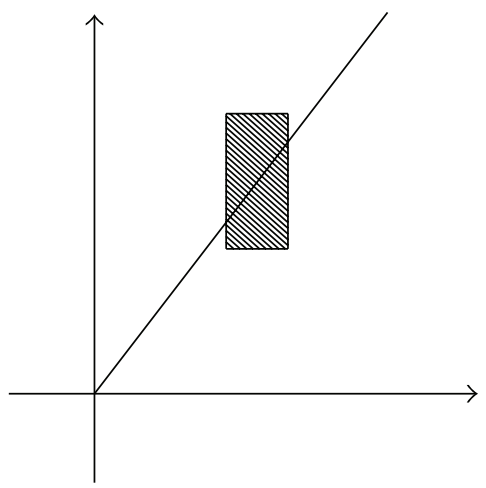

(d)

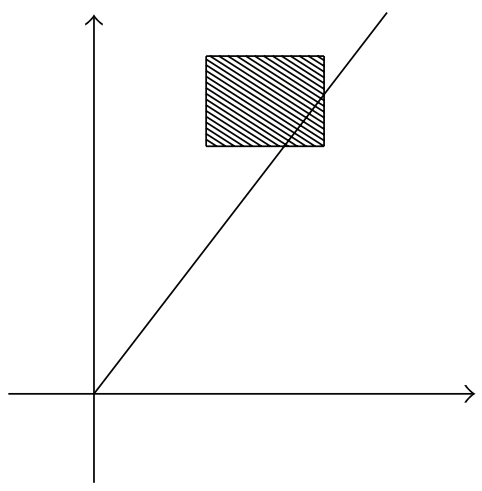

(b)

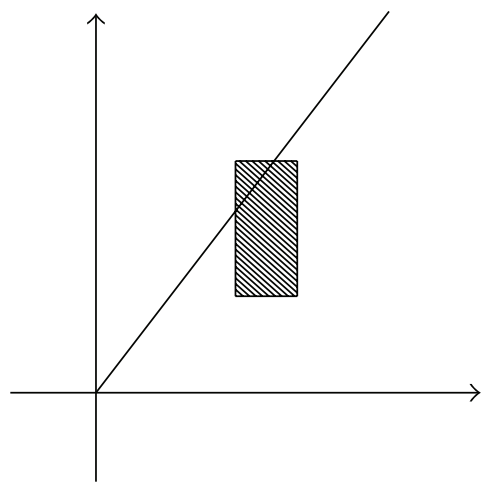

(e)

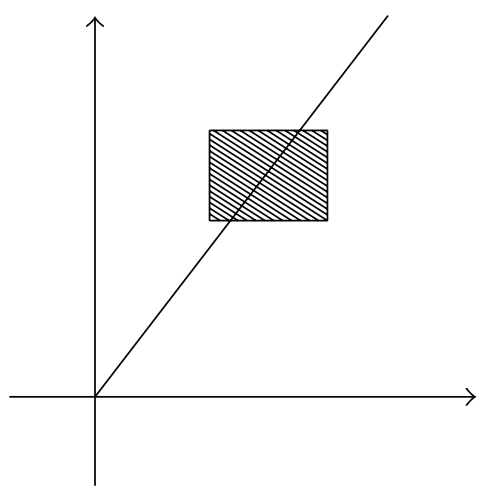

(c)

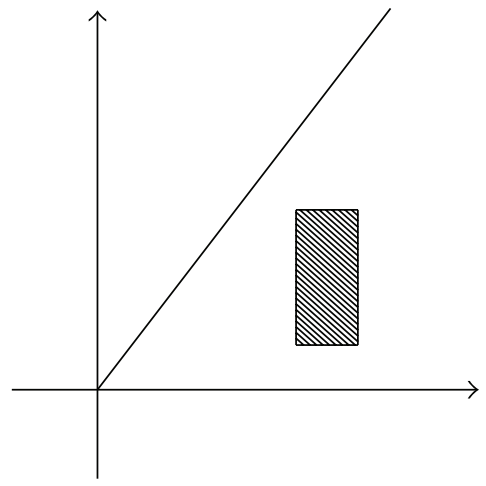

(f)

Figure 7: Positional relations between interval domain and threshold line.

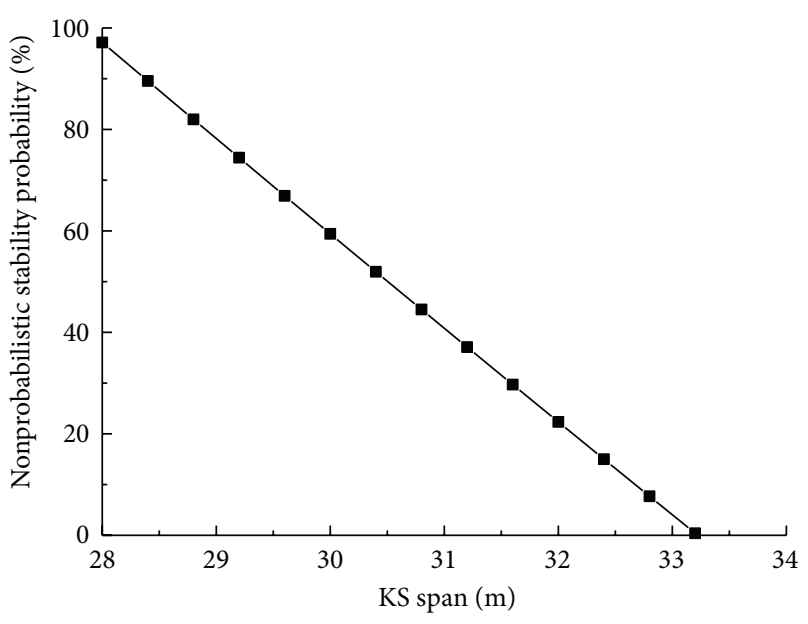

FIGURE 8: Variation relationship between nonprobabilistic stability probability and KS span.

be specific, the increase of KS span causes a steady decrease of nonprobabilistic stability probability with the stability probability dropping from nearly $100 \%$ to approximately 0 when KS span increases from 28 to $33 \mathrm{~m}$. Similarly, Figure 9 indicates a gradually decreasing trend. However, the growth of KS length shows a minor weakening effect on nonprobabilistic stability which declines merely $13 \%$ with KS length increasing from $200 \mathrm{~m}$ to $300 \mathrm{~m}$.

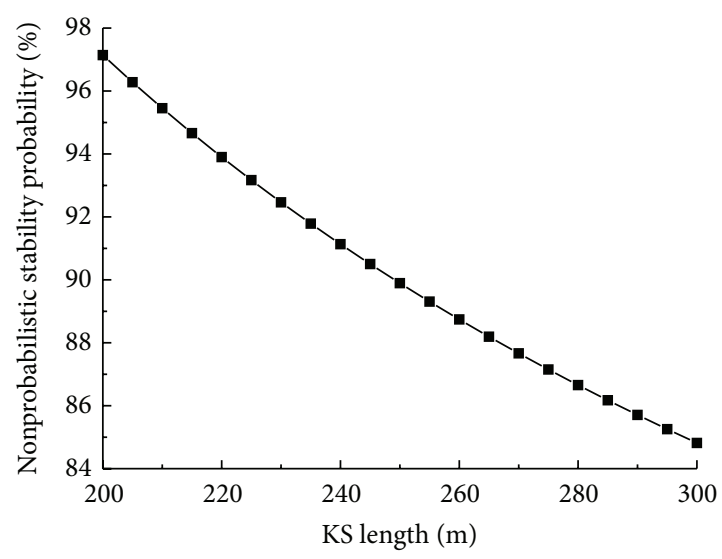

FIGURE 9: Variation relationship between nonprobabilistic stability probability and KS length.

On the contrary, the rise of KS thickness enhances the KS stability probability as shown in Figure 10. Comparatively, thickness, boosting the nonprobabilistic stability probability from 0 to $100 \%$ by merely 2 -meter growth, plays a more dominative role in the stability of KS.

5.2. Uncertainty Levels Analysis. Here we define the uncertain intervals of friction angle and cohesion as $\varphi \in[(37.304-$ $\left.\alpha)^{\circ},(38.938+\alpha)^{\circ}\right]$ and $c \in[(3.371-\beta) \mathrm{MPa},(3.722+\beta) \mathrm{MPa}]$, 


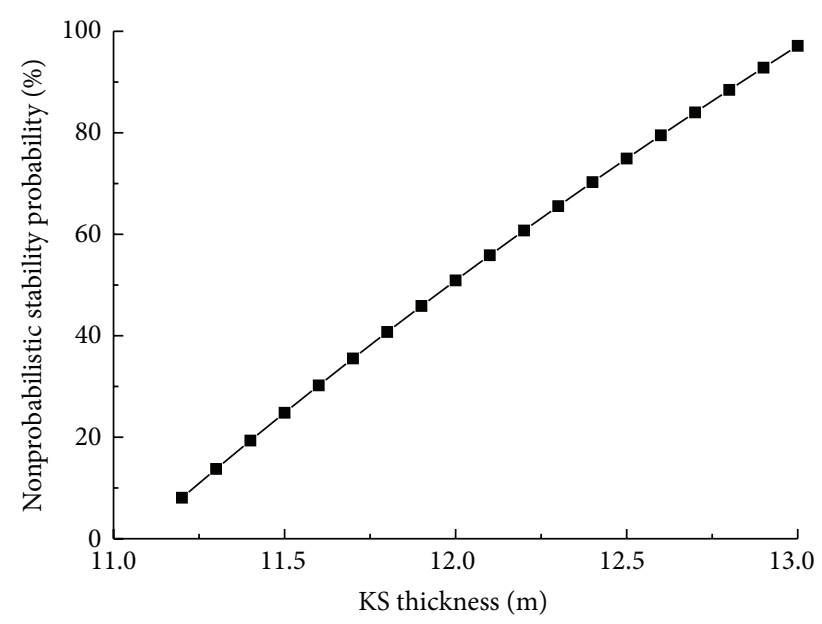

FIGURE 10: Variation relationship between nonprobabilistic stability probability and KS thickness.

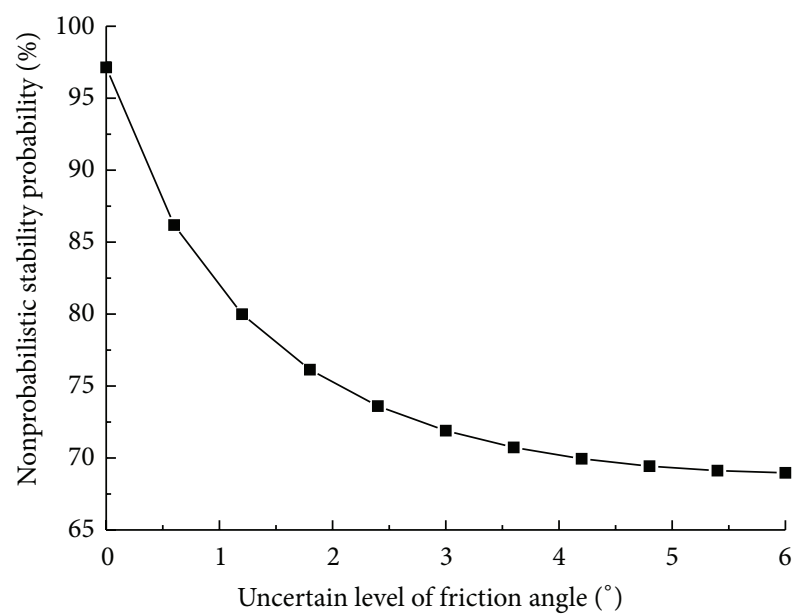

FIGURE 11: Variation relationship between nonprobabilistic stability probability and uncertain level of friction angle.

respectively. $\alpha$ and $\beta$ are defined as the uncertain levels of friction angle and cohesion, respectively.

We can figure it out that the nonprobabilistic stability probabilities in Figures 11 and 12 both experience a decline with the increase of uncertain levels. Compared with the effect of the uncertain level of friction angle, the uncertain level of cohesion shows a more sustainable weakening effect on KS nonprobabilistic stability probability.

\section{Conclusion}

Based on the typical KS failure features in Datong Diggings, China, the following conclusions can be reached through applying the nonprobabilistic reliability method to analyze the stability of KS.

(1) A shear failure model is proposed in this paper based on the typical failure model of KS in Datong Diggings.

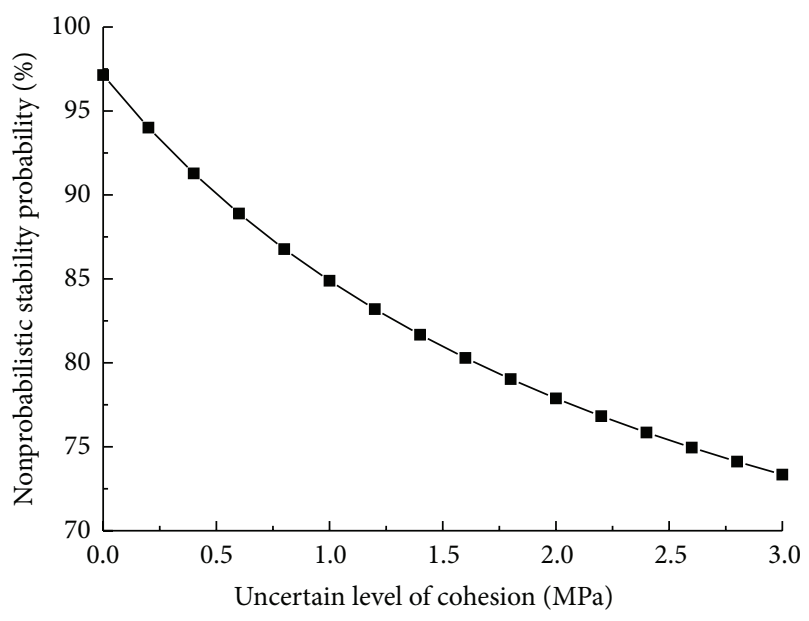

FIGURE 12: Variation relationship between nonprobabilistic stability probability and uncertain level of cohesion.

(2) Relating to the mechanical tests and in situ stress test, an allowable-safety-factor based nonprobabilistic stability assessment method is proposed and applied to evaluate the KS reliability.

(3) The effects of geometrical dimensions and uncertainty levels are further studied. While the increase of thickness significantly enhances the stability, the trends for the length and the span of KS both witness a steady decline. Besides, the increase of uncertainty levels of friction angle and cohesion both lead to decrease of KS stability probability.

(4) The sensitivity analysis indicates that thickness and span of KS have a great effect on the reliability of KS. The rock mass, however, is irregularly distributed in strata. Therefore, an intensive geological survey on the KS is essential for minimizing the hazardous roof cutting. One should also curtail the exposure time of the KS and guarantee timely support.

\section{Conflict of Interests}

The authors declare that there is no conflict of interests regarding the publication of this paper.

\section{Acknowledgments}

This research is supported by National Basic Research Program of China (also called 973 Program) (no. 2013CB227903) and State Scholarship Fund from the China Scholarship Council (Project no. 201306430001).

\section{References}

[1] S. S. Peng and H. S. Chiang, Longwall Mining, John Wiley \& Sons, New York, NY, USA, 1984.

[2] B. H. G. Brady and E. T. Brown, Rock Mechanics for Underground Mining, Chapman \& Hall, London, UK, 1992. 
[3] M. G. Qian, X. X. Miao, and J. L. Xu, The Key Stratum Theory for Control of Strata Movement, China University of Mining \& Technology Press, Xuzhou, China, 2003.

[4] M. G. Qian, P. W. Shi, and J. L. Xu, Ground Pressure and Strata Control, China University of Mining and Technology Press, Xuzhou, China, 2010.

[5] J.-L. Xu, M.-G. Qian, and W.-B. Zhu, "Study on influences of primary key stratum on surface dynamic subsidence," Chinese Journal of Rock Mechanics and Engineering, vol. 24, no. 5, pp. 787-791, 2005.

[6] J. L. Xu and J. F. Ju, "Structural morphology of key stratum and its influence on strata behaviors in fully-mechanized face with super-large mining height," Chinese Journal of Rock Mechanics and Engineering, vol. 30, no. 8, pp. 1547-1556, 2011.

[7] X.-X. Miao, X.-B. Mao, Z.-W. Sun, and H. Pu, "Formation conditions of compound key strata in mining overlayer strata and its discriminance," Journal of China University of Mining and Technology, vol. 34, no. 5, pp. 464-467, 2005.

[8] J.-F. Ju, J.-L. Xu, and Q.-X. Wang, "Cantilever structure moving type of key strata and its influence on ground pressure in large mining height workface," Journal of the China Coal Society, vol. 36, no. 12, pp. 2115-2120, 2011.

[9] J. F. Ju, J. L. Xu, and W. B. Zhu, "Influence of key strata structure motion on end-face fall in full-mechanized face with super great mining height," Journal of China Coal Society, vol. 39, no. 7, pp. 1197-1204, 2014.

[10] R. Q. Xiong, "Investigation of mechanism of roof failure due to weighting over great extent," Journal of China Coal Society, vol. 20, pp. 38-41, 1995.

[11] Z. Y. Hou, B. Yu, and J. F. Zhou, "Analysis of total collapse of hard roof in Datong mined area," Coal Mining Technologies, vol. 13, no. 1, pp. 62-65, 2008.

[12] D.-Y. Liu, H.-T. Sun, and Y. Zhang, "A model of shear slipping of overlying strata under mining disturbance," Rock and Soil Mechanics, vol. 31, no. 2, pp. 609-614, 2010.

[13] R. Chowdhury and B. N. Rao, "Hybrid high dimensional model representation for reliability analysis," Computer Methods in Applied Mechanics and Engineering, vol. 198, no. 5-8, pp. 753765, 2009.

[14] H. C. Elman, O. G. Ernst, D. P. O'Leary, and M. Stewart, "Efficient iterative algorithms for the stochastic finite element method with application to acoustic scattering," Computer Methods in Applied Mechanics and Engineering, vol. 194, no. 911, pp. 1037-1055, 2005.

[15] G. Allegri, S. Corradi, and M. Marchetti, "Stochastic analysis of the vibrations of an uncertain composite truss for space applications," Composites Science and Technology, vol. 66, no. 2, pp. 273-282, 2006.

[16] Q. Qin, D. J. Lin, and G. Mei, Theory and Applications: Reliability Stochastic Finite Element Methods, Tsinghua University Press, Beijing, China, 2006.

[17] Y. Ben-Haim and I. Elishakoff, Convex Models of Uncertainties in Applied Mechanics, Elsevier Science Publisher, Amsterdam, The Netherlands, 1990.

[18] Y. Ben-Haim, "Convex models of uncertainty in radial pulse buckling of shells," Transactions ASME, Journal of Applied Mechanics, vol. 60, no. 3, pp. 683-688, 1993.

[19] I. Elishakoff, P. Elisseeff, and S. A. L. Glegg, "Nonprobabilistic, convex-theoretic modeling of scatter in material properties," AIAA Journal, vol. 32, no. 4, pp. 843-849, 1994.
[20] Y. Ben-Haim, "A non-probabilistic concept of reliability," Structural Safety, vol. 14, no. 4, pp. 227-245, 1994.

[21] Y. Ben-Haim and I. Elishakoff, "Discussion on: a nonprobabilistic concept of reliability," Structural Safety, vol. 17, no. 3, pp. 195-199, 1995.

[22] S. X. Guo, Z. Y. Lu, and Y. S. Feng, "Non-probabilistic model of structural reliability based on interval analysis," Chinese Journal of Computational Mechanics, vol. 18, no. 1, pp. 56-60, 2001.

[23] S. X. Guo and Z. Z. Lu, "A procedure of the analysis of nonprobabilistic reliability of structural systems," Chinese Journal of Computational Mechanics, vol. 19, no. 3, pp. 332-336, 2002.

[24] S.-X. Guo, L. Zhang, and Y. Li, "Procedures for computing the non-probabilistic reliability index of uncertain structures," Chinese Journal of Computational Mechanics, vol. 22, no. 2, pp. 227-232, 2005.

[25] X. Wang, Z. Qiu, and Z. Wu, "Non-probabilistic set-based model for structural reliability," Chinese Journal of Theoretical and Applied Mechanics, vol. 39, no. 5, pp. 641-646, 2007.

[26] J. Liu, M. Wang, and Q. X. Qing, "A new structural nonprobabilistic reliability analysis method," Chinese Journal of Solid Mechanics, vol. 35, no. 4, pp. 378-383, 2014.

[27] National Bureau of Standards, Technical Regulations for NonCoal Open Pit Slope Engineering (GB51016-2014), China Standard Press, Beijing, China, 2014. 


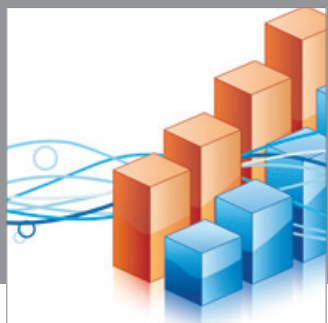

Advances in

Operations Research

mansans

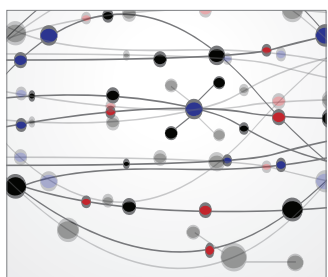

The Scientific World Journal
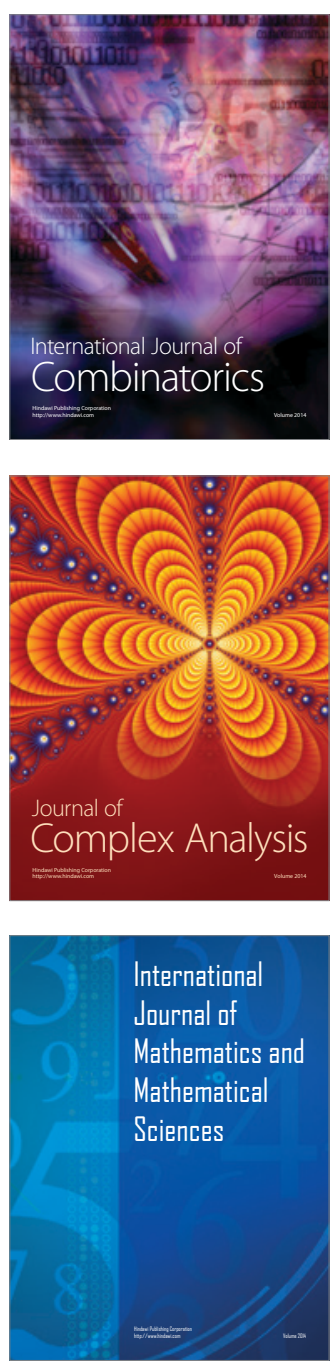
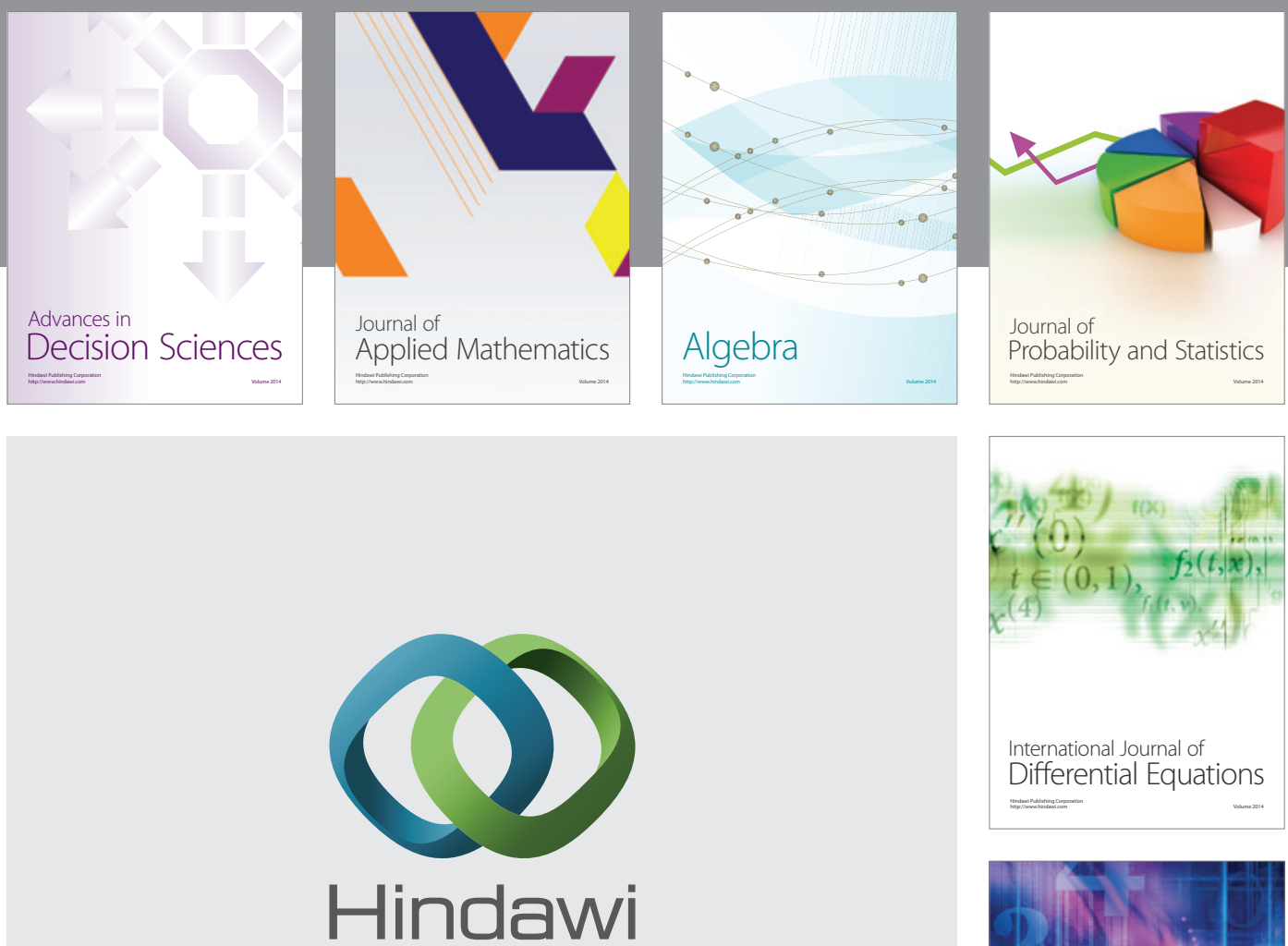

Submit your manuscripts at http://www.hindawi.com
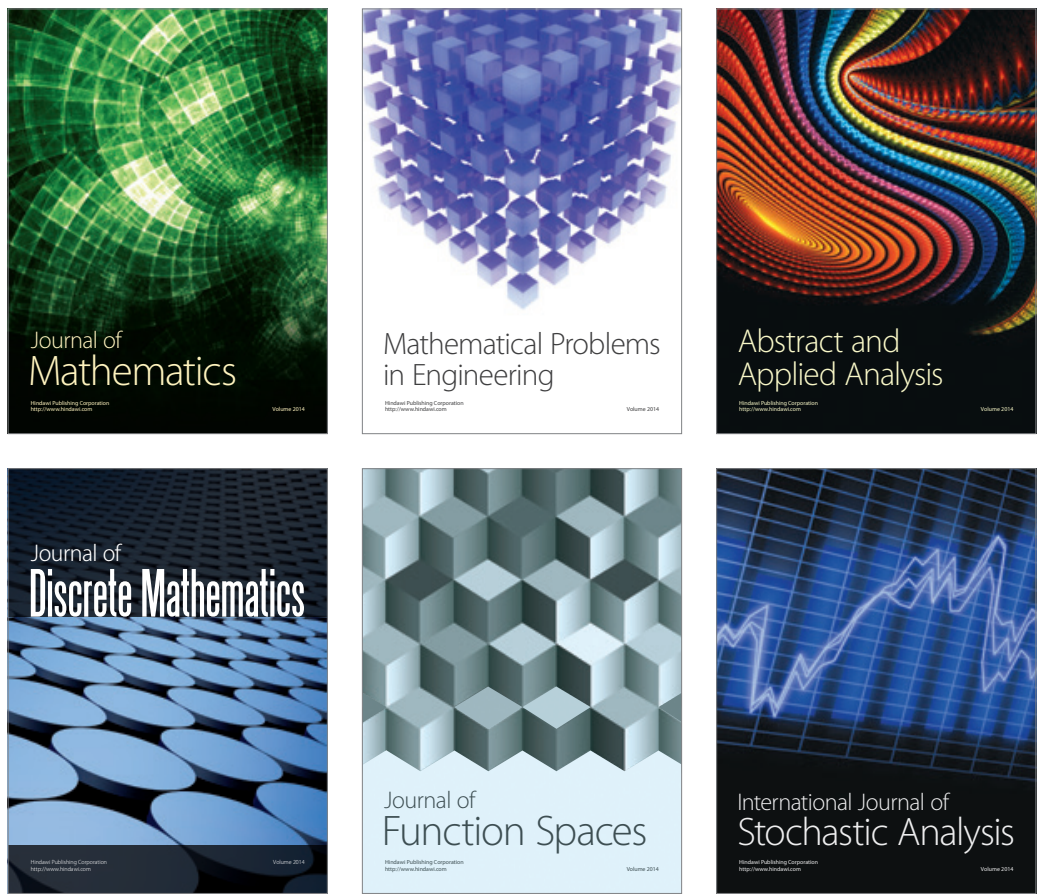

Journal of

Function Spaces

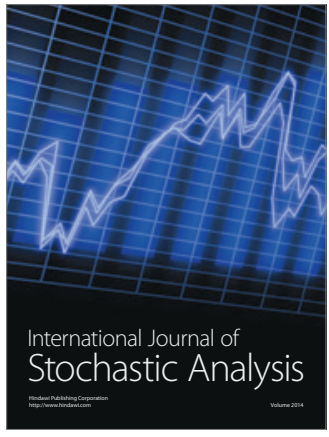

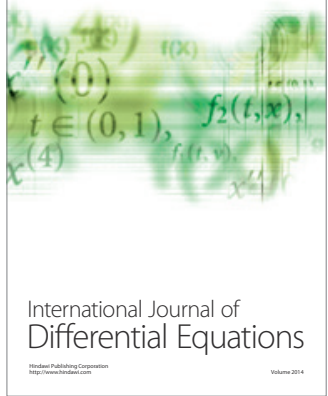
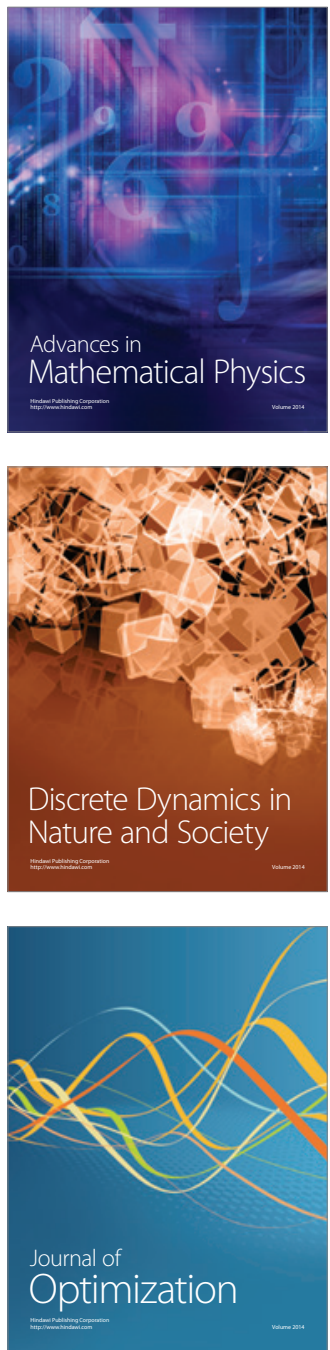